\title{
Information technology as a tool to improve the efficiency of the housing market
}

\author{
Mariia Ermilova ${ }^{1, *}$, Sergey Laptev ${ }^{1,2}$ \\ ${ }^{1}$ Plekhanov Russian University of Economics, Financial Management Department, 117997, Moscow, Russia \\ ${ }^{2}$ Financial University under the Government of the Russian Federation, Department of Corporate Finance and Corporate Governance, \\ 125993, Moscow, Russia
}

\begin{abstract}
Information technologies are increasingly entering our lives, absorbing almost all industries. The housing market is no exception. This is especially important within the framework of increasing the efficiency of operations in the housing market while simultaneously reducing a certain list of risks and additional costs. Evaluating the experience of several developed countries, we can conclude that information technologies have significantly improved the state of the market and its financing. In Russia, in contrast to foreign countries, the existing information infrastructure of the housing market is ineffective. This has an impact on the quality of financing for the industry, does not fully provide all the opportunities available in world practice. In addition, the reduction in funding for the industry does not allow the construction of higher quality housing, which would have a significant impact on the environment. The study used methods of modeling, systems analysis, induction. The results of the study made it possible to show the influence of the information infrastructure of the housing market on making decisions on the construction or purchase of residential real estate. In addition, the influence of a developed information infrastructure on financing the housing market in the context of the digital transformation of the economy was determined.
\end{abstract}

\section{Introduction}

Currently, all major sectors of the economy, including construction, are influenced by digitalization trends. The development of information technology makes it possible to solve several global problems, including those related to financing a specific industry. When deciding on the construction of housing, a careful analysis of information regarding both the construction procedure itself and the financing of construction and the purchase of housing by buyers in the future is required. The housing market is a field where the interests of both representatives of the construction industry and citizens involved in real estate transactions must be connected and satisfied.

The object of the research is the information infrastructure of the housing market in Russia, formed considering foreign experience.

The subject is the economic relations that are formed in the housing market using information technologies and in the process of functioning of subjects in the conditions of the information infrastructure of the market.

The aim of the work is to form an effective information infrastructure of the housing market and assess its impact on the financing of the construction and housing sectors. The study will solve the following tasks:

- the current information infrastructure of the housing market was analyzed;

- explored the possibilities of its improvement, taking into account the strengthening of trends in the digital transformation of the economy and the active development of information technologies;

- formulated the basic principles that the presented information infrastructure of the housing market must comply with in the context of the development of IT technologies;

- the influence of the improved information infrastructure on the financing of the housing market in the context of the development of information technologies was determined.

The hypothesis of the study is that the formation of an effective, well-built information infrastructure of the housing market makes it possible to increase the efficiency of decisions made by the subjects of the housing market in relation to transactions with residential real estate.

Research in the field of the impact of information technology on the environment, including various industries, has been conducted for more than a decade.

In economic theory, for a long period, there was an assumption that all market participants are equally available to all information. However, this assumption raised a number of doubts, which predetermined the need for a deeper analysis. Thus, one of the first researchers who noted the presence of asymmetric information was Kenneth J. Arrow in 1963 [1]. Later in 1970, Akerlof J. formed the market model with asymmetric information (The market for "Lemons": Quality Uncertainty and Market Mechanism) [2]. The results of the research and

* Corresponding author: masha080487@mail.ru 
further developments allowed the scientist, together with colleagues, to receive the Nobel Prize in Economics in the early 2000s for analyzing markets with imperfect information. A number of researchers have linked the asymmetry of information to markets such as the labor market. For example, J. Stigler back in 1962 [3], in his article, considered the relationship between information and the labor market (Stigler, 1962). In addition, some scholars have analyzed the impact of asymmetric information on taxation. Vickrey W.C. Proceedings [4] concerning the development of a new inheritance tax in Puerto Rico, the sequence of actions in progressive taxation and a number of other works on taxation, became the basis for the analysis of the profitability of the tax system, taking into account the asymmetry of information, published by Mirrlees J.-A. In 1997, the scientist published Information and Incentives: The Economy of Carrots and Carrots [5].

Stiglitz J.-Yu. also conducted research on information asymmetry problems for insurance companies [6]. In his research, the scientist was able to develop a mechanism for "reverse market adaptation", which meant that less informed market participants can get information from more informed ones. Further, together with other scientists, for example, S. Grossman, he investigated the influence of information asymmetry on financial markets (the Grossman-Stiglitz paradox) [7]. There have been other studies analyzing the role of information and its asymmetry in different markets [8, 9, 10], etc .). E.I. Khabibullina [11] in her study analyzed the influence of information asymmetry on the development of industry markets. D.A. Dobrynina analyzes how the asymmetry of information affects the market, how much negative consequences it carries [12]. Thus, all of these scientists came to the conclusion that the efficiency of markets and their participants can significantly decrease due to insufficient awareness of each of the parties.

With regard to the housing market and its financing, it can be said that the participants in the housing market and financial markets are often the same entities. In order to obtain financing, participants in the housing market turn to financial market instruments.

At the same time, as such, in-depth studies in the field of the influence of asymmetry of information on sectors of the economy, in particular, the housing market, despite its direct relationship with financial markets, have not been carried out. However, to date, due to the digital transformation of the economy and its other challenges, it is relevant to conduct research related to assessing the impact of the development of information technologies on segments of the economy, in particular, the construction and housing markets. This will improve the quality of their financing, which means, in general, will positively affect the functioning of these markets and the economy as a whole.

\section{Methods}

To obtain the most qualitative results, the work uses the methods of empirical and theoretical research, namely, methods of analysis, comparison, synthesis, inductive method, and modeling.

\subsection{Asymmetric information in the housing market}

The asymmetry of information is one of the reasons for the need for an information infrastructure for markets. The study revealed that this concept is mainly applicable to the field of information technology. The information infrastructure of the housing market, as such, has not previously been considered deeply enough by researchers. Basically, scientists considered the asymmetry of information in the field of insurance, taxation, and the functioning of financial markets. However, for the housing market, this is also an urgent problem that can be adjusted if there is a consistency in the formation and functioning of the information infrastructure of the housing market.

A prerequisite for the existence of asymmetric information on the housing market is the receipt of different information about the construction and purchase or sale of residential real estate by various market participants, as well as their interaction with financial markets in terms of the possibility of obtaining financing.

Information infrastructure in the housing market implies making the market more efficient. At the same time, it is assumed that this infrastructure will allow accumulating complete information from both private and public sources. Unity in the formation of an information base will reduce the influence of information asymmetry in decision-making by market entities. The main problem seems to be the multidirectionality and different content in the sources presented for general use.

The asymmetry of information on the housing market does not allow making a sufficiently informed decision regarding the construction of residential real estate by construction companies, as well as its acquisition by potential buyers. Fearing to get into the risk zone, the subjects reduce their potential demand, and often refuse such operations altogether. This makes it impossible to fulfill the plan for the construction of affordable housing for the population, the sale of the required volume of square meters. In addition, the pricing in the housing market, due to the asymmetry of information, may be formed insufficiently substantiated, taking into account the consumer capabilities of buyers.

\subsection{Information infrastructure of the Russian housing market}

The strategic stability of the housing market as one of the most important elements of the country's economic system can be achieved through the creation of an effective information infrastructure, which implies the formation of uniform information flows for all participants in the housing market. These streams allow data to be used to make decisions about the construction or purchase / sale of housing properties. 
Let us consider how the elemental structure of the information infrastructure of the Russian housing market can be represented.

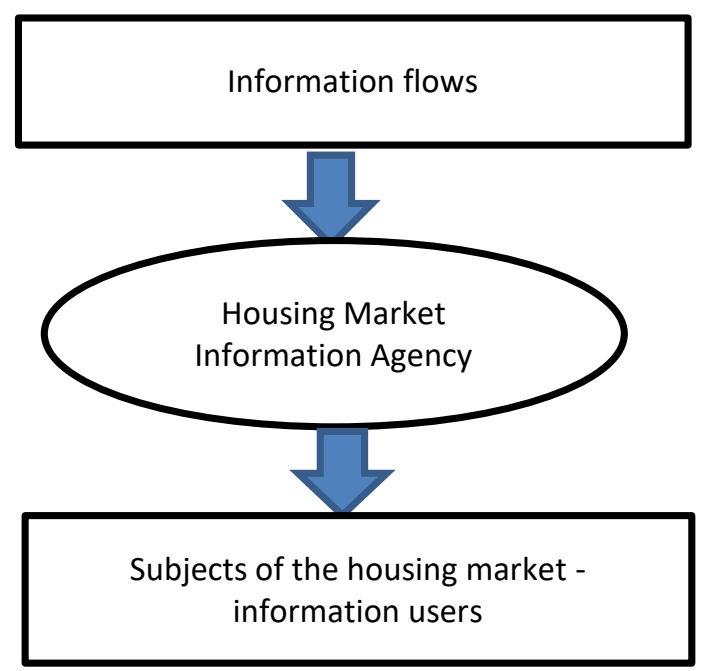

Fig. 1. Elementary structure of the information infrastructure of the housing market

Figure 1 shows the general elemental structure of the information infrastructure, which includes three main blocks. They contain the information itself, which will be accumulated and transmitted to the news agency. The news agency and the subjects of the housing market have a need to obtain prompt and up-to-date information on the functioning and financing of the housing market. The subjects are both consumers of housing objects, that is, buyers, and the construction companies themselves, and other participants - mainly suppliers of capital. The collected data should be provided to users based on the need for specific information for each of them, and not in full. Thus, it is necessary to ensure that each user can choose the amount of data that is required to make an informed decision regarding a residential property. The variability of the choice of the necessary information for each of its consumers should be ensured. At the same time, the content of information flows should be such as to reduce the possibility of information asymmetry for subjects.

From our point of view, the information infrastructure of the housing market must comply with the following principles:

- the unity of the database;

- the breadth of the information provided, including its maximum amount required for decision-making by the subjects of the housing market;

- efficiency of data stored in the generated database;

- the availability of this database to participants in the housing market, taking into account the possibility of ranking information, choosing the information necessary for a particular subject;

- transparency of the data provided;

- state financing of the information agency, as the main subject of the information infrastructure, which forms the necessary database.

\section{Results and discussion}

Integration of an information agency into the information infrastructure of the housing market, which will allow accumulating all relevant data on the functioning and financing of this market, provides several advantages:

- solution of the issue with the provision of relevant information to market participants;

- raising awareness of the subjects of the housing market about its work and sources of financing;

- providing real information on the list of instruments and mechanisms for financing the housing market, which will allow making the most informed decision based on the real solvency of the subject;

- growing demand from the population for residential real estate in view of obtaining a more complete picture of the functioning of developers and other entities involved in transactions in the housing market;

- reduction of risks for market participants associated with information "hunger";

- reducing the costs of market participants associated with the construction or acquisition of residential real estate in view of the receipt of the most relevant information;

- more careful control by the state, including allowing to reduce the corruption component in the functioning and financing of this market;

- improving the efficiency of decision-making in relation to the construction or purchase / sale of housing objects;

- growing demand for various instruments to finance construction or purchase of housing;

- ensuring the transparency of the functioning of the subjects of the housing market, as well as instruments of market financing;

- reduction in the number of fraudulent transactions in the field of housing finance.

At the same time, there are some disadvantages and risks in the organization of this entity:

- the need to increase budget funding by the state to ensure the creation and further functioning of the information agency. However, it should be noted here that with the effective work of the agency, a positive result can be achieved, which will improve the work of the market and thereby reduce a number of costs. Overall, the cumulative positive effect could exceed the estimated funding cost;

- the complexity of the organization of this entity and ensuring the promptness of the provision of information by available information sources;

- the complexity of interaction with the subjects of the housing market at the initial stages of operation.

It seems that it is important to include the task of organizing a single information agency in the state program for the development of the housing market and its financing (or national project).

In conclusion, it is advisable to assess the impact of the information infrastructure of the housing market on making decisions about the construction or purchase of 
housing, taking into account the presence of a single information agency.

The availability of information infrastructure and the main entity that will accumulate data makes it possible to improve the financing procedure both from the state and from other subjects of the housing market. Information flows to potential developers and buyers allow to expand opportunities and make more informed decisions about financing and any other transactions.

As soon as all information is accumulated and analyzed in the news agency, such information can be transferred to the main market participants who are interested in its maximum level of quality and completeness. It is shown that the state is both a provider of information and its consumer. The information infrastructure, which includes all information flows from different databases, redirects it to the information agency, which accumulates and analyzes, forming information flows that are uniform for all in terms of content. It is the news agency that should be called upon to further ensure the highest quality financing for market entities.

The expanded database, which is collected by the news agency, allows the subjects of the housing market to obtain the effect of increasing the volume of construction and increasing, to a greater extent, effective demand from buyers. The data will not be stored separately, which means they will be uniform in content and in the time of receipt and processing. An especially important principle that must be observed is the efficiency of the information received.

The volume of financing of the housing market with its properly organized information infrastructure should be rationally distributed, thereby ensuring constant financial flows between the subjects of the housing market, increasing the availability of housing for the population, helping to increase the volume of construction of high-quality housing and achieving the indicators planned in state programs.

Figure 2 shows the impact of a developed information infrastructure on financing the housing market in the context of the digital transformation of the economy.

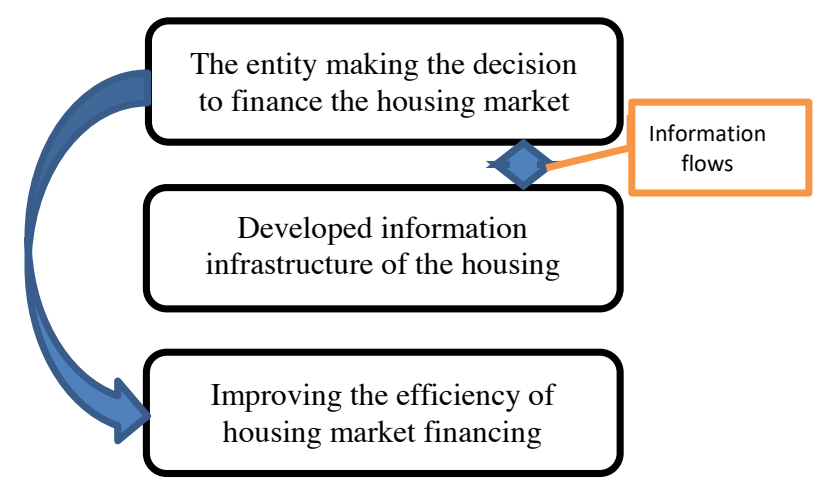

Fig. 2. The impact of a developed information infrastructure on financing the housing market in the context of the digital transformation of the economy
By accumulating information flows into a single database, a developed information infrastructure of the housing market is being created. Receiving the amount of information from this base, the subject of the housing market makes an informed decision in a shorter time frame, the amount of financing can be rationally increased or decreased, since the information received is more correct and the risks of the subjects can be reduced. Thus, it has a positive effect on the entire system of market financing and allows to increase its efficiency.

The processes of digitalization of the economy will continue and it is important to ensure that the development of various industries, including the construction sector and other subjects of the housing market, is in line with the trends of digital transformation of the global economy. It is the improved information infrastructure of the housing market that should enable this.

\section{Conclusion}

So, as a result of the study, the following results were obtained and conclusions were formulated:

- the developed information infrastructure of the housing market allows to improve its functioning and expand financing opportunities, as well as make this financing more rational;

- currently, there are scattered sources of information from which market participants receive the necessary data. Some data in different sources may differ significantly, which creates additional problems for market participants. At the same time, as such, the information infrastructure exists, but is not an efficiently functioning system;

- the formation of a single information agency is required, which accumulates all information on the housing market and the possibilities of its financing into a common base;

- the information infrastructure of the housing market can have a significant impact on decisions about construction and purchase / sale of housing. The fragmentation of data creates an information "hunger". The presence of a unified database makes it possible to increase the efficiency of the decisions made regarding the financing of the housing market, especially in the context of the digital transformation of the economy.

- the improved information infrastructure of the housing market ensures an informed decision on financing the acquisition or construction of residential real estate, reduces the degree of uncertainty in forecasting changes in supply and demand for real estate.

- the author presents a mechanism for financing the creation of an information infrastructure agency for the Russian housing market, indicating the need for state funding, as well as the possibility of attracting private investment.

- the influence of the information infrastructure of the housing market on making decisions on the construction or purchase of housing was determined 
and presented in the form of a diagram indicating the role of the unity of information flows for consumers of this information in order to ensure more rational financing of the market.

- the influence of a developed information infrastructure on the financing of the housing market in the context of the digital transformation of the economy is revealed, which suggests the possibility of a more effective redistribution of financial flows within the market, which can improve its quality and ensure the fulfillment of socially significant tasks of the state.

In general, the availability of the information infrastructure of the housing market allows not only to increase the efficiency of financing the industry, but also has a positive impact on the environment. This is reflected in the fact that housing, construction processes are improving in quality. An additional plus is the possible increase in the environmental friendliness of actions carried out in the housing market.

\section{References}

1. K.J. Arrow, Amer. Econ. Rev., 53, 941-973 (1963)

2. G.A. Akerlof, The Quarter. Jour. of Econ., 84, 488500 (1970)

3. G.J Stigler, Jour. of politic. econ., 70 (1962).

4. W.S. Vickrey, Agenda for progressive taxation. (N.Y.: The Ronald press comp,1947)

5. J.A. Mirrlees, Information and incentives: The economics of carrots and stuck (Les Prix Nobel, 360379, 1997)

6. J.E. Stiglitz, The Amer. Econ. Rev., 69 (2), 339-345 (1979)

7. S.J. Grossman, J.E. Stiglitz, The Amer. Econ. Rev., June, 393-408 (1980)

8. J.R. Green, Harvard Inst. Econ. Res., 284 (1973)

9. R. Kihlstrom, L. Mirman, Bell. Journal Econ. Spring, 6, 357-376 (1975)

10. E. Fama, Jour. Finance, 25, 383-417 (1970)

11. E.I. Khabibullina, Econ. and soc., 5-2 (18), 241-245 (2015).

12. D.A. Dobrynina, Theory and prac. of mod. sci., 3 (9), 773-776 (2016) 